\title{
ATIVIDADE ANTIMITÓTICA E APOPTOTICA PROVOCADAS POR EXTRATO DE UMBURANA EM SISTEMA TESTE VEGETAL
}

\author{
ANTIMITOTIC AND APOPTOTIC ACTIVITY CAUSED BY UMBURANA \\ EXTRACT IN VEGETAL TEST SYSTEM
}

\author{
Matheus Dias Santos ${ }^{1}$; Bárbara Dantas Fontes Soares ${ }^{2}$
}

DOI: https://doi.org/10.31692/978-65-991061-7-0.110-120

\begin{abstract}
RESUMO
Muitas plantas de uso popular têm sido utilizadas para o tratamento de doenças, porém, podem apresentar propriedades tóxicas e precisam ser analisadas, pois, pode ser um risco para a saúde humana. Assim, o objetivo deste trabalho foi analisar os efeitos do extrato aquoso de Amburana cearensis (umburana) na divisão e apoptose celular. Extrato aquoso das sementes foi obtido por maceração e trituração a seco, com posterior diluição em água destilada a uma concentração final do de $20 \mathrm{~g} . \mathrm{L}^{-1}$. Radículas tratadas com o extrato foram fixadas em carnoy e as lâminas montadas pelo método de esmagamento e analisadas em microscópio óptico. $\mathrm{O}$ delineamento experimental foi o inteiramente casualizado com cinco tratamentos $(0,24,48$, 72 e $96 \mathrm{~h}$ de exposição) e quatro repetições de 20 sementes de alface. A ação antimitótica do extrato foi verificada pela análise do índice mitótico (IM), enquanto que a apoptose celular foi constatada pelo percentual de células em processo de morte celular e necrose das raízes. Os resultados foram submetidos à análise de variância (teste F) e as médias comparadas pelo teste Tukey a 5\% de probabilidade. Verificou-se no controle negativo um alto índice de divisão celular e ausência de células apoptóticas, no entanto, após $48 \mathrm{~h}$ de exposição ao extrato aquoso de amburana, a divisão celular foi completamente suprimida e o índice de células apoptóticas aumentou gradualmente, chegando a 100\% de morte celular. Adicionalmente, observou-se necrose das radículas, conseqüência do processo de morte das células e da ausência de multiplicação celular das radículas. Assim, conclui-se que o extrato aquoso de Amburana cearensis possui ação antimitótica e apoptótica sobre as células de alface.
\end{abstract}

Palavras-Chave: Lactuca sativa, morte celular, índice mitótico, planta medicinal, citotoxicidade.

\begin{abstract}
Many plants of popular use have been used for the treatment of diseases, however, they can present toxic properties and they need to be analyzed, therefore, can be a risk for human health. Thus, the objective of this work was to analyze the effects of the aqueous extract of Amburana cearensis (umburana) on cell division and apoptosis. Aqueous extract of the seeds was obtained by maceration and dry grinding, with subsequent dilution in distilled water to a final concentration of $20 \mathrm{~g} . \mathrm{L}^{-1}$. Radicals treated with the extract were fixed in carnoy and the slides were assembled by the crushing method and analyzed under an optical microscope. The experimental design was the completely randomized with five treatments $(0,24,48,72$ and $96 \mathrm{~h}$ of exposure) and four replications of 20 lettuce seeds. The antimitotic action of the extract was verified by the analysis of the mitotic index (IM), whereas the cellular apoptosis was verified by the percentage of cells in the process of cell death and necrosis of the roots. The results were submitted to analysis of variance ( $\mathrm{F}$ test) and the means compared by the Tukey test at 5\% probability. A high index of cell division and absence of apoptotic cells was observed in the negative control, however, after $48 \mathrm{~h}$ exposure to the aqueous amburana
\end{abstract}

\footnotetext{
${ }^{1}$ Agronomia, Universidade Estadual do Sudoeste da Bahia, matheusdiassantos2013@gmail.com

2 Doutorado: Universidade Estadual do Sudoeste da Bahia, barbarafontes@uesb.edu.br
} 
extract, cell division was completely suppressed and the apoptotic cell index gradually increased, reaching $100 \%$ of cell death. In addition, necrosis of the rootlets was observed, as a consequence of the cell death process and the absence of cell multiplication of the radicles. Thus, it is concluded that the aqueous extract of Amburana cearensis has antimitotic and apoptotic action on the lettuce cells.

Keywords: Lactuca sativa, cell death, mitotic index, medicinal plant, cytotoxicity.

\section{INTRODUÇÃO}

A Caatinga, bioma singular de ocorrência exclusiva no Brasil, apresenta uma gama de espécies vegetais lenhosas, entre essas, destaca-se a Amburana cearensis, árvore pertencente à família Fabaceae e conhecida no Brasil pelos nomes de amburana, umburana, cerejeira-rajada, cumaru, cumaru-das-caatingas, cumaru-do-ceará, apresenta porte regular, podendo atingir até 10m de altura na caatinga (LORENZI e MATOS, 2002). São utilizadas casca e sementes por possuírem atividade antinflamatória e broncodilatadora devido à presença dos ativos químicos cumarina e flavonoides e suas sementes são ricas em compostos fenólicos, sendo comumente utilizadas pela cultura popular no tratamento de doenças como dor de barriga, reumatismo, tosse, bronquite, asma espasmos muscular e também como analgésico (ALMEIDA et al., 2010).

No entanto, Vieira et al., (2009) alerta que muitas plantas medicinais de uso popular podem possuir propriedades tóxicas, exigindo cuidados com a sua utilização e dosagens, a fim de se evitar danos à saúde humana.

Alguns autores verificaram que substâncias nocivas á saúde humana com efeitos tóxicos e mutagênicos podem ser liberados em chás de plantas medicinais (VICENTINI et al., 2001; VIEIRA et al., 2009; BEZERRA; DINELLY e OLIVEIRA, 2016). Estudos comprovam que muitas plantas produzem aleloquímicos, estas substâncias têm o potencial de inibir ou mesmo favorecer o processo germinativo de outras plantas, assim como interferir no processo de divisão celular (PATCHANEE, MONTINEE e CHAMROON, 2010). O modo de ação dessas substâncias parece ocorrer por meio de sinalização secundária que podem ocasionar alterações tanto fisiológicas quanto genéticas, influenciando processos a nível molecular e celular (FERREIRA e BORGHETTI, 2004).

Vários mecanismos de ação dos aleloquímicos foram listados por Resende et al., (2003), os quais podem comprometer os processos de respiração, fotossíntese, relações hídricas, nível de fitormônios, abertura de estômatos, disponibilidade mineral, etc. Almeida (2008), em revisão sobre o estresse oxidativo provocado por alelóquímicos, reuniu informações que indicam que a maior parte dos aleloquímicos são metabólitos secundários com atuação variada que afetam um grande número de reações bioquímicas, resultando em 
diferentes modificações fisiológicas nas plantas, como na atividade enzimática, divisão e estrutura de células, permeabilidade das membranas e captação de íons, culminado na redução ou inativação da germinação e crescimento das plantas.

Muitos aleloquímicos das plantas também possuem efeito citotóxico, genotóxico e mutagênicos, cujas ações podem ser verificadas pelas alterações cromossômicas e do ciclo mitótico de muitas espécies (DIAS et al. 2014; MELLO et al., 2013; IGANCI et al., 2006; CÂNDIDO et al., 2013). Abreu (1997), estudando extratos produzidos a partir das folhas de angico-vermelho (Anadenanthera peregrina), verificou a ocorrência de decréscimo do índice mitótico em células de alface com o aumento das concentrações do extrato. Resultado semelhante foi observado por Cândido et al., (2013) em alface e cebola.

Algumas espécies apresentam alta sensibilidade à presença de aleloquímicos e podem manifestar, portanto, tolerância ou resistência aos mesmos. Baseando-se nesta característica, algumas espécies foram padronizadas como plantas-indicadoras ou plantas testes, as quais, devido à sensibilidade aos aleloquímicos, são indicadoras da sua presença. Entres as plantasindicadoras as mais utilizadas estão o alface (Lactuca sativa L.), o tomate (Lycopersicum esculetum M.) e a cebola (Allium cepa), as quais também reúnem outras características interessantes, como a germinação rápida e uniforme e um grau de sensibilidade com o qual se permitem expressar resultados a baixas concentrações (FERREIRA e ÁQUILA, 2000).

Deste modo, são necessárias pesquisas que revelem os efeitos do extrato de $A$. cearensis sobre o ciclo celular e na produção de apoptose celular. Em cebola, foi comprovado que o extrato de A. cearensis comprometeu o índice mitótico, diminuindo o mesmo conforme o maior tempo de exposição, além de efeito genotóxico (MELLO et al., 2013), bem como prejuízos na germinação, no crescimento radicular e no desenvolvimento das plântulas de cebola (MANO, 2006), sorgo (SILVA et al., 2006), alface e rabanete (FELIX, ONO e ARAÚJO, 2010;). Todos estes efeitos podem estar associado a ação de componentes presentes na planta, como a cumarina e compostos fenólicos, sobretudo flavonoides (SILVEIRA e PESSOA, 2005).

Assim, o presente trabalho tem por objetivo avaliar os possíveis efeitos citotóxicos de extrato aquoso de A. cearensis em células meristemáticas de alface, por meio da análise do ciclo celular e apoptose da célula.

\section{FUNDAMENTAÇÃO TEÓRICA}


Substâncias conhecidas como citotóxica, genotóxicas e mutagênica são todas àquelas que causam danos à célula e ao material genético. Portanto, a avaliação do potencial de atividade citotóxica, por meio da avaliação do índice mitótico e morte celular provocadas pelo extrato da Amburana cearensis sobre as células da alface, planta-indicadora, será de fundamental importância, uma vez que muitos compostos presentes nas plantas possuem atividade tóxica que podem causar danos celulares ou genéticos. Tais danos podem afetar processos vitais como a duplicação e a transcrição gênica, bem como alterações cromossômicas, levando até mesmo à ocorrência de processos cancerosos e morte celular em animais. Em plantas, existem vários estudos identificando alterações nos processos fisiológicos, celulares e cromossômicos produzidas por substâncias com potencial tóxico, os chamados aleloquímicos (RESENDE et al., 2003; FERREIRA e BORGHETTI 2004; PATCHANEE, MONTINEE e CHAMROON, 2010).

Portanto, uma vez que a população faz amplo uso dos fitomedicamentos e poucos estudos têm sido realizados para avaliar a toxicidade potencial dos fitoterápicos, os quais podem apresentar vários agravos à saúde, investigações com o objetivo de estabelecer a atividade, esclarecer mecanismos de ação, identificar componentes ativos, ou mesmo, investigar os possíveis efeitos tóxicos e/ou citotóxicos produzidos por vegetais utilizados na medicina popular, são muito importantes (VICENTINI et al., 2001).

\section{METODOLOGIA}

A pesquisa é de natureza qualitativa, do tipo experimental e foi desenvolvida no Laboratório de Citogenética da Universidade Estadual do Sudoeste da Bahia (UESB), Campus de Vitória da Conquista/BA.

Sementes de Amburana cearensis foram coletadas em árvores matrizes localizadas na Fazenda Santo Antônio das Flores, situada no município de Anagé, BA.

Para a obtenção do extrato aquoso de A. cearensis a uma concentração final de $20 \mathrm{~g} . \mathrm{L}^{-1}$ sementes recém colhidas foram maceradas por ação mecânica a seco e trituradas em liquidificador, para uma melhor refinamento da mesma, com transferência de $20 \mathrm{~g}$ de macerado para $1000 \mathrm{~mL}$ de água destilada fervente, após homogeneização, a solução foi mantida em repouso em temperatura ambiente até esfriamento e coada em papel filtro (LORENZI e MATOS, 2002).

O delineamento experimental utilizado foi inteiramente casualizado (DIC) com cinco tratamentos: $(0,24,48,72$ e $96 \mathrm{~h}$ de exposição) e quatro repetições de 20 sementes de alface, totalizando 20 placas e 80 sementes por tratamento. Em cada parcela experimental (placa de 
Petri identificadas de acordo com o tratamento e forradas com papel germitest) foram colocados $5 \mathrm{~mL}$ de água destilada, suficiente para umedecer o papel e, em seguida, foram distribuídas uniformemente com o auxílio de uma pinça as 20 sementes sobre o papel e cobriu-se com outra camada de papel germitest para manter a umidade das sementes.

Após 24 horas, as sementes recém germinadas foram submetidas aos tratamentos: (0h) controle negativo, onde as radículas foram umedecidas com $5 \mathrm{~mL}$ de água destilada e mantidas por mais $24 \mathrm{~h}$ em água; nos demais tratamentos, as radículas foram submetidas à $5 \mathrm{~mL}$ de solução do extrato aquoso de sementes de A. cearensis, por períodos de exposição de $24 \mathrm{~h}$; 48h; 72h e 96 horas, com preparo de nova solução para cada tratamento.

Após cada tratamento, as radículas foram coletadas e passaram por 3 lavagens de 10 minutos em água destilada e fixadas em carnoy (3 etanol (P.A):1 ácido acético (P.A)) efetuando-se 3 trocas de fixador em intervalos de 15 minutos. Posteriormente, o material foi mantido em refrigeração por pelo menos 24 horas e, após, transferidos para álcool etílico $70 \%$ e armazenados a $5^{\circ} \mathrm{C}$ até o uso.

No preparo das lâminas, as radículas foram lavadas 3 vezes em água destilada com intervalos de 5 minutos e, na seqüência, foram hidrólisadas em $\mathrm{HCl} 1 \mathrm{~N}$ a $60^{\circ} \mathrm{C}$ por 7 minutos. Interrompeu-se a hidrólise em água destilada gelada e corou-se os meristemas com orceína acética a $2 \%$ por 30 minutos. As lâminas foram confeccionadas gotejando-se ácido acético $45 \%$ sobre a radícula com posterior excisão e fragmentação da região meristemática com o auxílio de um bisturi; cobriu-se o material com lamínula realizando batidas sequenciais sobre a mesma e, posteriormente, envolvendo-as com papel toalha para a aplicação de pressão com o polegar ao conjunto lâmina-lamínula, de modo a favorecer o espalhamento das células e retirada do excesso de corante (GUERRA e SOUZA, 2003, modificado).

As lâminas foram analisadas com o auxílio de microscópio óptico Nova Optical Systems, com objetiva de 40X. Para o cálculo do índice mitótico (IM), contou-se o número das células em cada fase da divisão mitótica (intérfase, prófase, metáfase, anáfase e telófase), e dividiu-se o número de células em mitose pelo total de células analisadas, o resultado foi multiplicado por 100. Analisou-se 5 lâminas por repetição, totalizando 20 lâminas por tratamento e observou-se 100 células por lâmina, o que totaliza 2000 células por tratamento, com exceção dos tempos de 72 e 96 horas, onde grande parte das células foram destruídas pela ação dos tratamentos.

As imagens foram registradas por uma câmera digital SAMSUNG de 13 mega pixels.

As análises estatísticas foram realizadas pela análise de variância (teste F) e as médias obtidas dos diferentes tratamentos comparadas pelo teste Tukey a $5 \%$ de probabilidade, 
usando-se o programa SAEG (Sistema de Análises Estatísticas e Genéticas), versão 9.1, Ribeiro Junior (2001).

\section{RESULTADOS E DISCUSSÃO}

Ficou evidente os efeitos causados às células de alface, à medida que aumentava o tempo de exposição ao extrato de Amburana cearensis, como pode ser observado na tabela 1, onde os tratamentos apresentaram diferenças estatísticas relevantes. A citotoxicidade de amburana nas células de alface foi notória neste trabalho (Figura 1 A e B).

Tabela 1. Número de células em interfase, em divisão, índice mitótico e apoptose em células meristemáticas de alface mantidas em água destilada por $24 \mathrm{~h}$ sem extrato (controle negativo $(\mathrm{CN})-0 \mathrm{~h}$ ) e submetidas ao extrato aquoso de sementes de amburana por 24h; 48h; 72h e 96h. Fonte: Própria.

\begin{tabular}{lllllll}
\hline Tratamento & $\begin{array}{l}\text { Total de } \\
\text { células }\end{array}$ & $\begin{array}{l}\text { Células } \\
\text { intérfase }\end{array}$ & $\begin{array}{l}\text { em } \\
\text { Células } \\
\text { em divisão }\end{array}$ & Índice mitótico (\%) & Apoptose (\%) \\
\hline $0 \mathrm{~h}(\mathrm{CN})$ & 2000 & 698 & 1302 & $65,1 \mathrm{a}$ & $0,00 \mathrm{a}$ \\
$24 \mathrm{~h}$ & 2000 & 1924 & 76 prófases & $3,8 \mathrm{~b}$ & $60,60 \mathrm{~b}$ \\
$48 \mathrm{~h}$ & 2000 & 2000 & 0 & $0,0 \mathrm{c}$ & $90,05 \mathrm{c}$ \\
$72 \mathrm{~h}$ & 580 & 580 & 0 & $0,0 \mathrm{c}$ & $100,00 \mathrm{~d}$ \\
$96 \mathrm{~h}$ & 610 & 610 & 0 & $0,0 \mathrm{c}$ & $100,00 \mathrm{~d}$ \\
\hline
\end{tabular}

Médias seguidas pela mesma letra na coluna não diferem entre si pelo Teste Tukey $(\mathrm{P}>0,05)$.

Figura 1: Aspecto geral das células de alface submetidas aos tratamentos quanto às fases da divisão celular e seu efeito no índice mitótico (IM). Fonte: Própria.
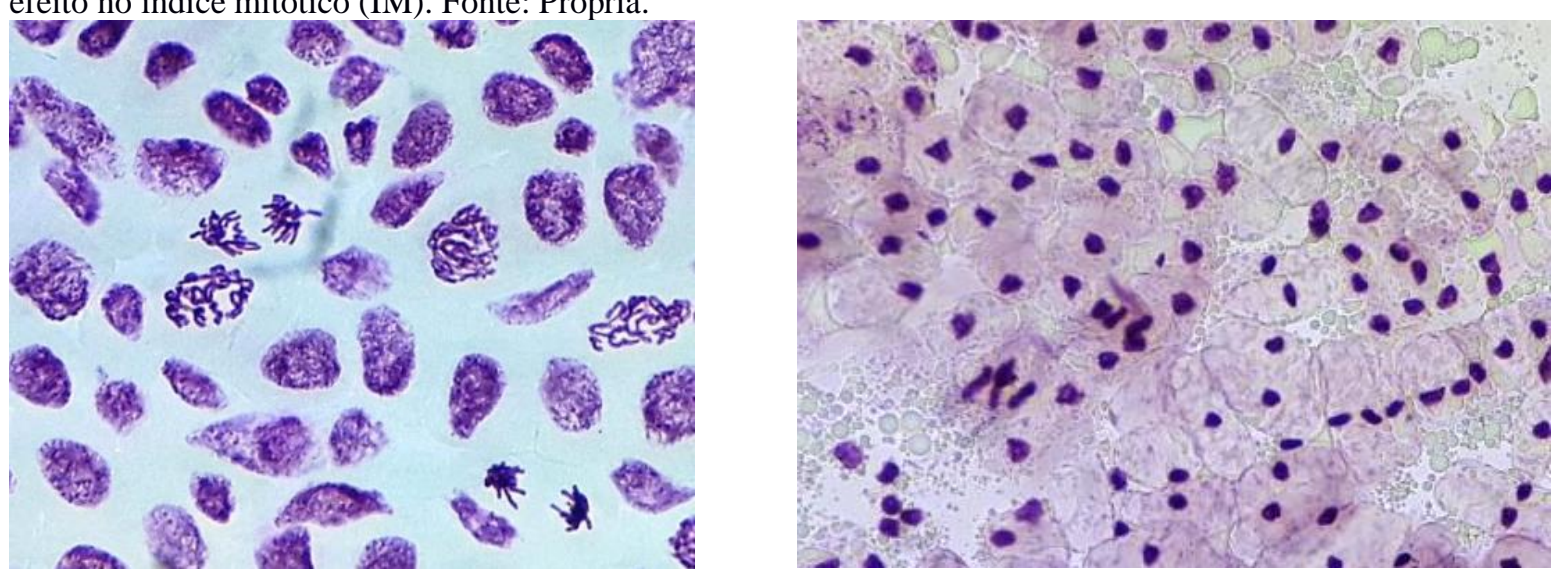

Aspecto geral das células de alface quanto às fases da divisão celular e seu efeito no índice mitótico (IM). 1A: Controle negativo (tratamento sem a presença do extrato de amburana) onde nota-se a atividade de divisão celular; enquanto que em 1B, constatou-se apenas a presença de células apoptóticas, com núcleo extremamente compactado, morfologia irregular e com presença de deformidades nas membranas, além de formação de grânulos com progressiva evolução para a formação de grandes vesículas. Fonte: Própria.

As avaliações citológicas das células meristemáticas de alface usadas como controle negativo (tempo 0h de exposição ao extrato) revelaram que as células encontravam-se em pleno processo de multiplicação, com alto índice de divisão celular $(65,1 \%)$ e presença de células em todas as fases do ciclo celular (Figura 1A), porém, a partir da exposição das mesmas ao extrato de amburana por 24h, foi observado um decréscimo substancial em termos quantitativos e qualitativos das células em divisão, uma vez que o índice mitótico decresceu 
para apenas $3,8 \%$, diferindo estatisticamente do controle e dos demais tratamentos, enquanto que a única fase presente na divisão celular após $24 \mathrm{~h}$ foi a fase de prófase (Tabela 1). Nos períodos de exposição subseqüentes (48, 72 e 96h), as células meristemáticas estavam respectivamente mais escassas com o decorrer do tempo destes tratamentos, evidenciando danos que acarretaram uma crescente eliminação das mesmas nos tecidos tratados, bem como a completa interrupção da divisão celular nas células que permaneceram no tecido, demonstrando um efeito antiproliferativo do extrato de amburana sobre as células de alface, além da ocorrência de decréscimo de crescimento e necrose nas radículas. Dessa forma, o índice mitótico se igualou a $0 \%$ para esses tratamentos e diferiram estatisticamente do controle negativo e do tempo de exposição de $24 \mathrm{~h}$, onde ainda houve um pequeno número de células em divisão.

Estes resultados podem ser comparados com os estudos realizados por DIAS et al., (2014), os quais verificaram a ocorrência de efeito genotóxico e antiproliferativo de Mikania cordifolia sobre o ciclo celular de cebola, com redução do índice mitótico em todos os tratamentos em relação ao controle negativo, assim como aos achados no trabalho realizado por Coelho et al., (2013), ao verificarem o potencial genotóxico e antiproliferativo em extrato foliar de Echinodorus longiscapus, conhecido popularmente como erva-do-brejo e chapéu-decouro, demonstrando que com o aumento das concentrações do extrato e, conseqüentemente, o aumento dos compostos fenólicos e flavonóides avaliados, ocorreu um efeito antiprolifertivo na concentração do extrato de $24 \mathrm{~g} \cdot \mathrm{L}^{-1}$, caracterizado pela inibição do ciclo celular da cebola, usada como planta bioindicadora. Dalla Nora et al., (2010), correlacionaram o efeito antiproliferativo ocasionado por extrato aquoso de Mikania glomerata em raízes de cebola à grande quantidade de cumarina (1,2-benzopirona), além de outros compostos que também estão presentes na Amburana cearensis e que podem explicar os resultados encontrados neste trabalho, tanto na diminuição do índice mitótico após 24 horas de exposição das radículas de alface ao extrato, como a total inibição da divisão celular observada nos tempos de exposição de 48, 72 e 96h. Silva et al., (2006) relatam que a Amburana cearensis apresentou efeito alelopático na germinação e desenvolvimento de plântulas de sorgo, atribuindo estes efeitos à cumarina, o mesmo efeito foi observado por Felix, Ono e Araújo, (2010) na germinação de rabanete e alface, provocados pela amburana..

Pesquisas como as realizadas por Dias et al., (2014); Mello et al., (2013); Iganci et al., (2006), demonstram o potencial da ação de substâncias aleloquímicas presentes em plantas medicinais, verificadas pelas alterações cromossômicas e do ciclo mitótico. Em estudo realizado por Mello et al., (2013) o extrato de A. cearensis testado em Allium cepa levou à 
ocorrência de decréscimo do índice mitótico à medida que aumentou-se o tempo de exposição ao extrato. Knoll et al., (2006), evidenciaram a capacidade antriproliferativa de $P$. polystachyum pela inibição da divisão celular em A. cepa, conforme o aumento da concentração das infusões. Fachinetto e Tedesco (2009) também observaram inibição da divisão celular, bem como alterações celulares provocados por extrato aquoso de Baccharis trimera e B. articulata, indicando a ocorrência de atividade antiproliferativa e mutagênica dos extratos através do teste de A. cepa.

Assim, de acordo com Dias et al., (2014) a análise do índice mitótico permite verificar a interferência de compostos produzidos por algumas plantas na proliferação celular de muitas espécies.

Os resultados evidenciaram que, concomitantemente ao efeito antiproliferativo provocado pelo extrato aquoso de Amburana cearensis, também ocorreu gradativo aumento do número de células em apoptose (Figura 1B), conforme o aumento de tempo de exposição, com percentagem de células em apoptose que variam de 0\% no controle negativo a $100 \%$ de células apoptóticas no maior tempo de exposição, com diferenças estatísticas expressivas (Tabela 1).

Estes resultados são condizentes com as observações acerca dos índices de divisão mitótica, uma vez que no controle negativo as células estavam em diferentes fases do ciclo mitótico, com $65 \%$ das células em plena divisão celular e $35 \%$ em intérfase, enquanto o número de células apoptótica foi de $0 \%$, porém, após $24 \mathrm{~h}$ de exposição ao extrato de amburana, o percentual de divisão celular cai drasticamente para $3,8 \%$, enquanto que o número de células em apoptose aumenta acentuadamente para 61\%, já nos tempos de 48, 72 e 96h, enquanto o percentual de divisão celular foi de $0 \%$ para todos os tempos, os percentuais de células apoptóticas sofreram considerável elevação de 60 até 100\%, respectivamente, demonstrando o grande potencial destrutivo evidenciado pelo aumento significativo do número de células em morte celular depois de prolongada exposição ao extrato de amburana à concentração de $20 \mathrm{~g} . \mathrm{L}^{-1}$, o que pode estar associado ao desencadeamento do processo de necrose nas raízes de alface nos tempos de exposição superiores a 48h, caracterizado tanto pelo escurecimento das radículas quanto pela redução do seu crescimento, consequência do processo de morte das células e da ausência de multiplicação celular das radículas.

Deste modo, Sanevas, Sunohara e Matsumoto (2007) propõem que o extrato de Hapalosiphon sp. eleva a atividade das endonucleases responsáveis pela degradação do DNA nas raízes de A. cepa, resultado em morte das células, sendo essa a maior causa da redução do crescimento radicular observada no estudo. 
Os resultados encontrados corrobora com os achados de Vieira et al., (2009), os quais demonstraram o potencial efeito da infusão de capítulos florais de camomila, nas concentrações de 10, 15 e 20g.L $\mathrm{L}^{-1}$, na produção de elevado número de células apoptóticas, no decréscimo do índice de divisão celular e na necrose de radículas de cebola, mesmo na menor concentração empregada, o que confirma os dados de Cardoso et al., (2006), o qual faz uma correlação positiva entre a quantidade de compostos presentes no extrato de Byrsonima crassa e o número de células em apoptose.

Muitas plantas com qualidades terapêuticas e de uso na medicina popular apresentam propriedades tóxicas, que justificam muito cuidado com a sua utilização, embora, em muitos casos, a simples presença destas substâncias não desqualifique o seu uso medicinal, porém, requer estudos que indiquem cuidados com a dosagem, se apresentam efeitos cumulativos, ou até mesmo se são impróprias para o consumo. Assim, os resultados obtidos neste trabalho, usando-se a alface como planta-teste (indicadora), devem ser considerados como um alerta, pois, segundo De Smet, 2004, embora os produtos naturais sejam amplamente considerados de menor risco em comparação com as drogas sintéticas, eles não são completamente livres da possibilidade de toxicidade ou outros efeitos adversos.

\section{CONCLUSÕES}

O extrato aquoso de Amburana cearensis apresentou efeito citotóxico em células meristemáticas de alface, tal efeito foi verificado pela expressiva diminuição do índice mitótico após $24 \mathrm{~h}$ de exposição ao extrato e completa paralisação da divisão celular nos tempos subsequentes, bem como o processo de apoptose, desencadeamento a morte das células e necrose das radículas.

\section{REFERÊNCIAS}

ABREU, J. C. Potencial alelopático do angico-vermelho (Anadenanthera peregrina (L.) speg.): efeitos sobre a germinação de sementes e ciclo mitótico de plântulas de alface (Lactuca sativa L.) e canafístula (Peltophorum dubium (Spreng.) Taub.), Lavras: (Dissertação) UFLA, 1997.

ALMEIDA, G. D. Estresse oxidativo em células vegetais mediante aleloquímicos. R. Fac. Nac. Agron., v.61, n.1, p.4237-4247, 2008.

ALMEIDA, J. R. G. S. et al. Amburana cearensis - uma revisão química e farmacológica. Scientia Plena, [s.1], v.6, n.11, 2010.

BEZERRA, C. M.; DINELly, C. M. N.; OliveIRA, M. A. S. Avaliação da toxicidade, citotoxicidade e genotoxicidade do infuso de Malva-Santa (Plectranthus barbatus Lamiaceae) 
sobre o ciclo celular de Allium cepa. Revista Eletrônica de Farmácia, v.13, n.4, p.220-228, 2016.

CANDIDO, A. C. S.; SILVA, C. B.; SIMIONATTO, E.; BIGATON, D.; SCALON, S. P. Q.; PERES, M. T. L. P. Phytotoxic activity of Croton doctoris S. Moore. Ciênc. Rural, v.43(4), p.645-652, 2013.

CARDOSO, C. R. P.; CÓLUS, I. M. S.; BERNARDI, C. C.; SANNORNIYA, M.; VILEGAS, W.; VARANDA, E. A. Mutagenic activity promoted by amentoflavone and methanolic extract of Byrsonima crassa Niendenzu. Toxicology, v.225, p.55-63, 2006.

COELHO, A. P. D.; FRESCURA, V. D.; MAMBRI, A. P.; BOLIGON, A. A.; TEDESCO, S. B. Avaliação dos compostos fenólicos e potencial genotóxico e antiproliferativo do extrato de Echinodorus longiscapus Arech. Enciclopédia Biosfera, v.9, n.16, p.2698-2709, 2013.

DALLA NORA, G, PASTORI, T; LAUGHINGHOUSE, IV HD; CANTO-DOROW, TS; TEDESCO, SB. Antiproliferative and genotoxic effects of Mikania glomerata (Asteraceae). Biocell, 34: 85-101, 2010.

DE SMET, P. A. G. M. Health risks of herbal remedies: An update. Clin Pharmacol Ther 76: 1-17, 2004.

DIAS, M. G.; CANTO-DOROW, T. S.; COELHO, A. P. D.; TEDESCO, S.B. Efeito genotóxico e antiproliferativo de Mikania cordifolia (L. F.) Willd. (Asteraceae) sobre o ciclo celular de Allium cepa (L.). Revista Brasileira de Plantas Medicinais, v.16, n.2, p.202-208, 2014.

FACHINETTO, J. M.; TEDESCO, S. B. Antiproliferative and mutagenic activities of aqueous extract of Baccharis trimera (Less.) A. P. de Candolle and Baccharis articulata (Lam.) Pers. (Asteraceae) on the Allium cepa test system. Rev. bras. plantas med. [online]. 2009, v.11, n.4, p.360-367. ISSN 1516-0572

FELIX, R. A. Z; ONO, E. O; ARAÚJO, F. P. Efeitos alelopáticos de extrato de Amburana cearensis na germinação de sementes de rabanete. Cultivando o Saber. Cascavel, v.3, p.18$31,2010$.

FERREIRA, A. G.; AQUILA, M. E. A. Alelopatia: uma área emergente da ecofisiologia. Revista Brasileira de Fisiologia Vegetal, v.12, p.175-204, 2000.

FERREIRA, A. G.; BORGHETTI, F. Germinação: do básico ao aplicado. Porto Alegre: Artmed, 2004. 324p.

GUERRA, M.; SOUZA, M. J. Como observar cromossomos: um guia de técnica em citogenética vegetal, animal e humana. São Paulo: Funpec. 2003, 131p.

IGANCI, J. R. V.; BOBROWSKI, V. L.; STEIN, V. C.; ROCHA, B. H. G. Efeito do extrato aquoso de diferentes espécies de boldo sobre a germinação e índice mitótico de Allium cepa L. Arquivos do Instituto Biológico, 73: 79-82, 2006.

KNOLL, M. F.; SILVA, A. C. F.; CANTO-DOROW, T. S; TEDESCO, S. B. Effects of Pterocaulon polystachyum DC. (Asteraceae) on onion (Allium cepa) root-tip cells. Genetics and Molecular Biology, 29 (1): 539-542, 2006. 
LORENZI, H.; MATOS, F. J. A. 2002. Plantas medicinais no Brasil: nativas e exóticas. Nova Odessa: Plantarum. 2002, 512p.

MANO, A. R. O. 2006. Efeito alelopático do extrato aquoso de sementes de cumaru (Amburana cearensis S.) sobre a germinação de sementes, desenvolvimento e crescimento de plântulas de alface, picão-preto e carrapicho. Dissertação Mestrado em Agronomia, Centro de Ciências Agrárias, Universidade Federal do Ceará, Fortaleza CE, Brasil. 102 p.

MELlO, V. S.; VIEIRA, A.; MIRANDA, D. P.; TEIXEIRA, A. D.; ARSBURG, I. V. Genotoxicidade da infusão de Amburana cearensis (Allemão) A.C. Smith. pelo sistema teste Allium cepa. In: I SEMINÁRIO DE BIODIVERSIDADE E AGROECOSSISTEMAS AMAZÔNICOS, Alta Floresta. Genética e melhoramento, 2013.

PATCHANEE, C.; MONTINEE, T.; CHAMROON, L. An allelopathic substance isolated from Zanthoxylum limonella Alston fruit. Scientia Horticulturae, Misson, v.125, p.411-416, 2010.

REZENDE, C. P.; PINTO, J. C.; EVANGELISTA, A. R.; SANTOS, I. P. A. Alelopatia e suas interações na formação e manejo de pastagens. Boletim Agropecuário, Universidade Federal de Lavras, MG. (54):1-55, 2003.

RIBEIRO JÚNIOR, J. I. Análises Estatísticas no SAEG. Viçosa, UFV, 2001. 301p

SANEVAS, N.; SUNOHARA, Y.; MTSUMOTO, H. Characterization of reactive oxygen species-involved oxidative damage in Hapalosiphon species crude extract-treated wheat and onion roots. Weed Biol. Manag. 7(3):172-177, 2007.

SILVA, W. A.; NOBRE, A. P.; LEITES. A. P.; SILVA, M. S. C.; LUCAS, R. C. \& RODRIGUES, O. G. Efeito alelopático de extrato aquoso de Amburana cearensis A. Smith na germinação e crescimento de sementes de sorgo (Sorghum bicolor L.). Agropecuária Científica no Semi-árido 2(1):48-54, 2006.

SILVEIRA, E. R.; PESSOA, O. D. L. Constituintes micromoleculares de plantas do Nordeste com potencial farmacológico. Fortaleza: Editora Expressão Gráfica, 2005, 216 p.

VICENTINI, V. E. P; CAMPAROTO, M. L; TEIXEIRA R. O; MANTOVANI, M. S. 2001. Averrhoa carambola L., Syzygium cumini (L.) Skeels and Cissus sicyoides L.: medicinal herbal tea effects on vegetal and test systems. Acta Scientiarum, Maringá, v.23, n.2, p.593598, 2001.

VIEIRA, A.; GUIMARÃES, M. De. A.; DAVID, G. Q.; KASBURG, I.V.; CAMPOS, A. N. R. Efeito genotóxico da infusão de capítulos florais de camomila. Revista Trópica - Ciências Agrárias e Biológicas, v.3, n.1, p.8-13, 2009. 